\title{
Are there negative consequences of public reporting? The hype and the reality
}

Recently, a publication by DeVore and colleagues ${ }^{1}$ called into question the benefit of public reporting. In this study, the authors looked at the impact of public reporting on 30-day readmission rates among Medicare beneficiaries ( $\geq 65$ years of age) with 3 diagnoses: acute myocardial infarction (AMI), heart failure, and pneumonia. The authors analyzed the differences in trends of the 30-day readmission rate for the 3 years before and after the initiation of public reporting of these readmission rates in June 2009 on the Medicare Hospital Compare Web site. The result was that there appeared to be no impact of public reporting on 30-day readmission rates and would suggest that public reporting is not associated with improvement in outcomes.

Transparency through public reporting has been proposed as a major tool to improve healthcare quality, but the benefit and potential harm of public reporting remain topics of some debate. Among the potential harms of public reporting include a lack of cost effectiveness, lack of focus on important but not publicly reported metrics, risk aversion with denial of care to high-risk patients, as well as damage to both program and practitioner reputation. In this issue of the Journal, Dr Gaynor and colleagues ${ }^{2}$ were asked to provide a comment on the publication of DeVore and colleagues and, likewise, we were asked to comment on the paper of DeVore and colleagues well as the editorial by Gaynor and colleagues. ${ }^{2}$

As for the paper of DeVore and colleagues, we are concerned about the experimental design and thereby the conclusions. First, the endpoint of 30-day readmission rates is challenging for the public to understand. Early readmissions are a significant expense for the Centers for Medicare and Medicaid Services (CMS) and are estimated to cost CMS more than 10 billion dollars annually. ${ }^{3}$ The publication of readmission rates by CMS was postulated to provide transparency that would result in improvement in those rates. Indeed, the rate for readmission after AMI is decreasing. To account for a change on top of the

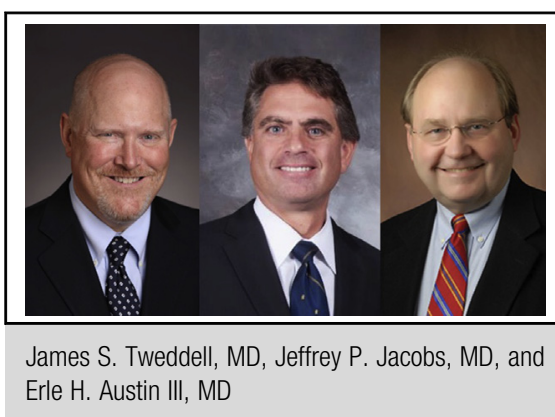

Central Message

Despite concerns of risk-averse behavior among physicians, the majority of studies suggest a net benefit to public reporting of outcome data.

See Article page 904

preexisting trend, DeVore and colleagues looked for a change in the rate of readmission before and after the initiation of public reporting. A positive impact of public reporting would require a deviation from the preexisting downward trend in the 30-day readmission rate. The assumption required by DeVore and colleagues would mean that as the readmission rate approaches zero the trend would remain constant, although clearly as the readmission rate decreases the curve will flatten to a point at which early the readmission rate can be reduced no further. The initial reduction in readmissions are likely "low hanging fruit," easily achieved with programmatic focus; however, after a point, the remaining readmissions may be quite difficult and even sometimes impossible to prevent. Whether over the course of this study the trend function remains constant is simply an assumption, and we cannot be certain that the inflection point where the curve begins to flatten has not already been reached.

There are other challenges with the study of DeVore and colleagues; first, the diagnostic groups and patient population are not ones in which public reporting would be likely to have a great impact. This is an older population and the diagnoses AMI, heart failure, and pneumonia do not permit much time to "shop around" for the best hospital. Second, although the rate of 30-day readmission rate is associated with cost, it may not be a direct indicator of quality care. ${ }^{4}$ What we really want to know is which hospital will provide our loved ones with the best outcome. Is a low 30-day readmission rate the best indicator of 
quality? If so, does the public understand this? The public is unlikely to be impacted by a difficult-to-understand metric when confronted with a severe unplanned illness where the greatest priority for hospital selection is ease of access and proximity. ${ }^{5}$ Finally, although public reporting might impact the hospitals and healthcare systems, they were already incentivized to lower 30-day readmission because this already was planned to impact reimbursement in 2012. It seems unlikely that public reporting would result in further pressure on these organizations for whom the financial incentive had been present for some time and who already knew their own data. Nevertheless, Gaynor and colleagues praised the DeVore study for the use of "robust statistical methodology" in an effort to evaluate the effectiveness of public reporting.

Risk aversion and denial of care to high-risk patients would unquestionably be a serious adverse impact of public reporting. This issue was not part of the study by DeVore and colleagues but instead was raised in the editorial by Gaynor and colleagues and merits a response based on the available data. Gaynor and colleagues, who asked for more "robust statistical methodology," cite (and with no sense of irony) a nonpeer-reviewed survey from the Telegraph, a newspaper in the United Kingdom, to support the contention that many heart surgeons are avoiding high-risk patients because they are concerned about their public reporting score card. ${ }^{6}$ Even a cursory review of this newspaper story identifies significant issues. This article suggested that approximately one third of cardiothoracic surgeons in the United Kingdom had "recommended a different treatment path" to avoid adding another death to their score card. The respondents appear to be saintlier than their nonresponding colleagues, as they reported this risk-avoidance behavior among $84 \%$ of their compatriots. It is noteworthy that there are 361 consultant cardiothoracic surgeons in the United Kingdom; thus, this newspaper article survey with 115 respondents captured less than one third of the cardiothoracic surgeons in the United Kingdom. ${ }^{7}$ The incongruous statistics of the Telegraph article notwithstanding, if a surgeon felt that surgery were likely to result in death, then wouldn't a "different treatment path" be a reasonable consideration?

So what are the data on risk-averse behavior and denial of care? Are there data beyond newspaper stories that could inform us on this issue? An actual peer-reviewed survey of practitioners in New York State by Burack and colleagues ${ }^{8}$ provides some insights. Their survey included 105 responses, equal to $69 \%$ of practicing heart surgeons in New York State. Sixty-two percent of respondents reported that they had refused to operate on at least one high-risk patient referred for coronary artery bypass grafting during the preceding year. At first glance, this sounds very concerning, but the authors looked at the characteristics of those who refused high-risk cases and found that they were more likely to have been in practice for less than 10 years, were less experienced, and were more likely to have a practice not exclusively committed to heart surgery.

These data are important for 2 reasons and suggest that risk-averse behavior may not be all bad. First, those individuals who were unwilling to take on high-risk cases were perhaps less well suited to take on these kind of cases. Second, the corollary of the survey data suggests that if not for public reporting, these less-qualified individuals would have been willing to take on high-risk cases. A number of factors may motivate a practitioner to take on a case that, in advance, they believe to be at or beyond his or her ability. Among the possible motivating factors are pride and a sense of duty but also financial factors. Financial incentive, although not usually overt, is a constant pressure that acts on us and the impact may be subtle and underappreciated.

Public reporting may result in a more conscientious, deliberate decision on the part of an individual practitioner to rationally weigh the risk of the specific procedure against his or her own abilities and experience. This impact of transparency at the provider level was well demonstrated in a study by Rex and colleagues. ${ }^{9}$ In this analysis, video recordings of screening colonoscopies were obtained before and after the practitioners were told their studies would be video recorded and evaluated by a third party for thoroughness. The average duration of examinations and the completeness of the studies improved dramatically after the practitioners were informed their work would be video recorded. This study involved well-trained, highly skilled colonoscopists at an academic center and yet their performance was significantly improved once they knew their work would be scrutinized.

At the macro level, the data on risk aversion are mixed. Joynt and colleagues ${ }^{10}$ showed that the rate of percutaneous coronary intervention (PCI) for AMI was lower in public reporting states but that there was no difference in mortality and no difference in the rates of coronary artery bypass grafting $(\mathrm{CABG})$ for AMI. A subsequent publication by the same group using the National Inpatient Sample suggested that states with public reporting were less likely to perform PCI on patients with AMI and also that the risk of mortality for AMI was greater in public-reporting states. $^{11}$

The potential for risk-averse behavior is not lost on state health departments. In 2005, New York State, the first state to mandate public reporting of cardiac surgery and PCI, allowed an exemption for patients with AMI and shock undergoing PCI to minimize the potential for risk-averse behavior. The PCI rate for AMI in New York State increased with the change in public reporting. ${ }^{12}$ It is noteworthy that in this study, the risk of mortality was not different between New York State and the other states before the change, but after the change in reporting, the risk of mortality in 
New York State dropped even further. It has been suggested that the public reporting of CABG outcomes by New York State has resulted in an outmigration of high-risk patients to neighboring states.

Omoigui and colleagues ${ }^{13}$ have suggested that the risk profile of New York State residents referred for CABG to the Cleveland Clinic increased as a consequence of public reporting, but this was in the face of an increase in mortality among all patients at the Cleveland Clinic. It is more plausible that the increase in the risk profile of patients at the Cleveland Clinic marks their transition from a regional to national referral center for patients with high-risk coronary artery disease. In contrast to the paper by Omoigui and colleagues, Peterson and colleagues ${ }^{14}$ found that the number of New York State citizens referred out of state for $\mathrm{CABG}$ decreased coincident with the initiation of public reporting.

Risk adjustment is essential not only to avoid risk-averse behavior but also to protect practitioners and patients. A recent episode in the United Kingdom emphasizes this point. The congenital heart surgery program at Leeds was suspended due to apparent excess mortality. ${ }^{15}$ Ultimately, when the results were reevaluated after appropriate risk adjustment, it was found that the program at Leeds was performing no differently than the other programs in the United Kingdom. ${ }^{16}$ Nevertheless, the lives of patients and families were disrupted profoundly, and the reputations of practitioners were impacted negatively.

Beyond the important fact that public reporting addresses the basic principle that "patients and their families have the right to know the outcomes of the treatments that they will receive," the predominance of data suggests an overall beneficial impact of public reporting. There has been a single randomized controlled trial evaluating the impact of public reporting that showed a decrease in mortality for AMI. ${ }^{17}$ There have been systematic reviews and meta-analyses as well. The Agency for Healthcare Research and Quality conducted a systematic review that was last updated in 2012 and found there is little data to suggest that public reporting results in reduced access to healthcare. ${ }^{18}$ They did identify some unintended provider behavior, such as assigning higher risk profiles to patients, withdrawal from the market, and lack of attention to unmeasured factors. The Agency for Healthcare Research and Quality found that although the potential for harm is cited frequently by commentators, the amount of research on harm is limited and most studies do not confirm the potential for harm. In a systematic review and metaanalysis, Campanella and colleagues ${ }^{19}$ reviewed published data from 1991 to 2014. Their meta-analysis included more than 5 million control and experimental events. They found that public reporting was associated with a $15 \%$ reduction in adverse events. Admittedly, the aforementioned work may not be directly applicable to the world of congenital heart surgery. Although we must continue to study the impact of public reporting to identify and mitigate negative consequences, the available studies indicate in total a positive effect and little negative consequence of public reporting.

In summary, public reporting of healthcare performance is new and potentially disruptive. Appropriate risk adjustment is critical to achieve effective and fair transparency, but there are little objective data of harm associated with public reporting. We must understand that the data are not ours to share but rather, these data belong to our patients and their families. Although we must continue to look at the cost effectiveness and meaningfulness of the metrics we report and how the public uses the data to make informed decisions, these efforts are likely to result in minor course changes and the effort to inform and educate our patients and their families must continue.

\section{References}

1. DeVore AD, Hammill BG, Hardy NC, Eapen ZJ, Peterson ED, Hernandez AF. Has public reporting of hospital readmission rates affected patient outcomes? Analysis of Medicare claims data. J Am Coll Cardiol. 2016;67:963-72.

2. Gaynor JW, Pasquali SK, Ohye RG, Spray TL. Potential benefits and consequences of public reporting of pediatric cardiac surgery outcomes. J Thorac Cardiovasc Surg. 2017;153:904-7.

3. Betancourt J, Tan-McGrory A, Kenst K. Guide to Preventing Readmissions Among Racially and Ethnically Diverse Medicare Beneficiaries. 2015. Available at: https://www.cms.gov/About-CMS/Agency-information/OMH/Downloads/ OMH_Readmissions_Guide.pdf. Accessed February 23, 2017.

4. Joynt KE, Jha AK. Thirty-day readmissions-truth and consequences. $N$ Engl J Med. 2012;366:1366-9.

5. Radford MJ. Does public reporting improve care? JAm Coll Cardiol. 2016;67:973-5.

6. Knapton S. One in three heart surgeons refuse difficult operations to avoid poor mortality ratings. The Telegraph. June 3, 2016. Available at: http://www. telegraph.co.uk/science/2016/06/03/one-in-three-heart-surgeons-refusedifficult-operations-to-avoid/.

7. Jarral OA, Baig K, Pettengell C, Baig K, Pettengell C, Uppal R, et al. National survey of UK consultant surgeons' opinions on surgeon-specific mortality data in cardiothoracic surgery. Circ Cardiovasc Qual Outcomes. 2016;9:414-23.

8. Burack JH, Impellizzeri P, Homel P, Cunningham JN Jr. Public reporting of surgical mortality: a survey of New York State cardiothoracic surgeons. Ann Thorac Surg. 1999;68:1195-200; discussion 1201-2.

9. Rex DK, Hewett DG, Raghavendra M, Chalasani N. The impact of videorecording on the quality of colonoscopy performance: a pilot study. Am J Gastroenterol. 2010;105:2312-7.

10. Joynt KE, Blumenthal DM, Orav EJ, Resnic FS, Jha AK. Association of public reporting for percutaneous coronary intervention with utilization and outcomes among Medicare beneficiaries with acute myocardial infarction. JAMA. 2012;308:1460-8.

11. Waldo SW, McCabe JM, O'Brien C, Kennedy KF, Joynt KE, Yeh RW. Association between public reporting of outcomes with procedural management and mortality for patients with acute myocardial infarction. J Am Coll Cardiol. 2015;65:1119-26.

12. McCabe JM, Waldo SW, Kennedy KF, Yeh RW. Treatment and outcomes of acute myocardial infarction complicated by shock after public reporting policy changes in New York. JAMA Cardiol. 2016;1:648-54.

13. Omoigui NA, Miller DP, Brown KJ, Annan K, Cosgrove D III, Lytle B, et al. Outmigration for coronary bypass surgery in an era of public dissemination of clinical outcomes. Circulation. 1996;93:27-33.

14. Peterson ED, DeLong ER, Jollis JG, Muhlbaier LH, Mark DB. The effects of New York's bypass surgery provider profiling on access to care and patient outcomes in the elderly. J Am Coll Cardiol. 1998;32:993-9.

15. Donnelly L, Hall M. 20 children may have died needlessly at heart unit. The Telegraph. March 29, 2013. Available at: http://www.telegraph.co.uk/news/9962097/ 20-children-may-have-died-needlessly-at-heart-unit.html. 
16. Dominiczak P. Sir Bruce Keogh admits that 'inaccurate data' led him to suspend children's heart surgery. The Telegraph. April 19, 2016. Available at: http://www. telegraph.co.uk/news/health/news/9980869/Sir-Bruce-Keogh-admits-thatinaccurate-data-led-him-to-suspend-childrens-heart-surgery.html.

17. Tu JV, Donovan LR, Lee DS, Wang JT, Austin PC, Alter DA, et al. Effectiveness of public report cards for improving the quality of cardiac care: the EFFECT study: a randomized trial. JAMA. 2009;302:2330-7.
18. Totten A, Wagner J, Tiwari A, O'Haire C, Griffin J, Walker M. Public Reporting as a Quality Improvement Strategy. Closing the Quality Gap: Revisiting the State of the Science. Evidence Report No. 208. 2012. Available at: http://www effectivehealthcare.ahrq.gov/reports/final.cfm. Accessed February 23, 2016.

19. Campanella P, Vukovic V, Parente P, Sulejmani A, Ricciardi W, Specchia ML The impact of public reporting on clinical outcomes: a systematic review and meta-analysis. BMC Health Serv Res. 2016;16:296. 